\title{
MANEJo QUímico DE Cyperus rotundus NA CulTuRA DA CANA-DE-AçÚCAR ${ }^{1}$
}

\author{
Chemical Control of Cyperus rotundus on Sugar-Cane Crop
}

\author{
VIVIAN, R. ${ }^{2}$, JAKELAITIS, A. ${ }^{3}$, CARNEIRO, P.M. ${ }^{4}$, SILVA, A.F. ${ }^{5}$, RIBEIRO JÚNIOR, J.I. ${ }^{6}$ e \\ SILVA, A.A. ${ }^{7}$
}

\begin{abstract}
RESUMO - Avaliou-se neste trabalho o efeito de doses $\left(1,0,1,5\right.$ e 2,0 $\left.\mathrm{kg} \mathrm{ha}^{-1}\right)$ e épocas de aplicação (pré ou pós-emergência) da mistura comercial ametryn + trifloxysulfuron-sodium no controle de Cyperus rotundus, na cultura da cana-de-açúcar, em comparação com $1,0 \mathrm{~kg} \mathrm{ha}^{-1}$ pré $+1,0 \mathrm{~kg} \mathrm{ha}^{-1}$ pós-emergência dessa mistura, $0,90 \mathrm{~kg} \mathrm{ha}^{-1}$ de sulfentrazone em préemergência, além das testemunhas com e sem capina. Maior efeito na redução de massa seca de $C$. rotundus foi proporcionado pelos tratamentos $1,0 \mathrm{~kg} \mathrm{ha}^{-1}$ pré $+1,0 \mathrm{~kg} \mathrm{ha}^{-1}$ pós e $2,0 \mathrm{~kg} \mathrm{ha}^{-1}$ em pós-emergência da mistura comercial de ametryn + trifloxysulfuron-sodium, respectivamente, com percentual médio de controle visual verificado nesses tratamentos de $86,8 \%$. Quanto aos efeitos sobre o número de manifestações epígeas de C. rotundus, com exceção do tratamento de $2,0 \mathrm{~kg} \mathrm{ha}^{-1}$ em pós-emergência, os correspondentes às aplicações em préemergência da mistura foram mais eficientes na sua redução. Todavia, o sulfentrazone isolado ou a menor dose de 1,0 kg ha ${ }^{-1}$ de ametryn + trifloxysulfuron-sodium em pré-emergência apresentaram baixa eficiência na redução de $C$. rotundus, com média de controle visual inferior a 40\%. Embora, nas aplicações em pré-emergência, a dose estimada de $1,25 \mathrm{~kg} \mathrm{ha}^{-1}$ não tenha diferido de $2,0 \mathrm{~kg} \mathrm{ha}^{-1}$ da mistura comercial, na redução da massa seca da parte aérea de C. rotundus, a aplicação em pós-emergência de $2,0 \mathrm{~kg}_{\text {ha }}{ }^{-1}$ apresentou efeito significativo em relação às demais doses, com ação prolongada no controle dessa espécie. Todos os tratamentos avaliados foram seletivos para a cana-de-açúcar, variedade RB 72454 .
\end{abstract}

Palavras-chave: trifloxysulfuron-sodium, ametryn, sulfentrazone, tiririca.

ABSTRACT - This work evaluated the effect of doses (1.0, 1.5, and $\left.2.0 \mathrm{~kg} \mathrm{ha}^{-1}\right)$ and periods of spraying (pre and post-emergence) of ametryn + trifloxysulfuron-sodium commercial mixture to Cyperus rotundus control, in sugar-cane crop, compared to $1.0 \mathrm{~kg} \mathrm{ha}^{-1}$ pre $+1.0 \mathrm{~kg} \mathrm{ha}^{-1}$ post-emergence of the same mixture, $0.90 \mathrm{~kg} \mathrm{ha}{ }^{-1}$ of sulfentrazone in pre-emergence, besides the treatments with and without weeding. A greater effect in dry mass reduction of $\mathbf{C}$. rotundus was provided by the treatments $1.0 \mathrm{~kg} \mathrm{ha} \mathrm{g}^{-1}$ pre $+1.0 \mathrm{~kg} \mathrm{ha}{ }^{-1}$ post and $2.0 \mathrm{~kg} \mathrm{ha}^{-1}$ of ametryn + trifloxysulfuron-sodium post-emergence commercial mixture, respectively, as the average percentage of visual control verified in those treatments was $86.8 \%$. About the effects on shoot number of $\mathbf{C}$. rotundus, except for the treatment $\left(2.0 \mathrm{~kg} \mathrm{ha}^{-1}\right)$ in post-emergence, the pre emergence treatments of the mixture were more efficient in reducing it. Yet, only sulfentrazone or the smallest dose $1.0 \mathrm{~kg} \mathrm{ha^{-1 }}$ of ametryn + trifloxysulfuron-sodium in pre-emergence showed low efficiency on $\mathbf{C}$. rotundus reduction, with average visual control lowe than 40\%. Although, in pre-emergence applications, the estimated dose of $1.25 \mathrm{~kg} \mathrm{ha}^{-1}$ did not differ from $2.0 \mathrm{~kg} \mathrm{ha-1}$ of the commercial mixture, in reducing dry mass of the aerial part of $\mathbf{C}$. rotundus, the application of $2.0 \mathrm{~kg} \mathrm{ha}^{-1}$ post-emergence presented significant effect, compared to the other doses, with remaining action control of this species. None of the treatments evaluated affected sugar-cane, variety RB 72454.

Keywords: trifloxysulfuron-sodium, ametryn, sulfentrazone, purple nutsedge.

Recebido para publicação em 11.4.2006 e na forma revisada em 10.11.2006.

Doutorando em Fitotecnia, Escola Superior de Agricultura "Luiz de Queiroz" - ESALQ/USP, 13418-900 Piracicaba-SP, <agrovivian@yahoo.com.br>; ${ }^{3}$ Professor da Fundação Universidade Federal de Rondônia - UNIR, Campus Rolim de Moura; ${ }^{4}$ Acadêmico do curso de Agronomia da Universidade Federal de Viçosa - UFV; ${ }^{5}$ Estudante de Mestrado em Fitotecnia, Departamento de Fitotecnia - DFT/UFV; ${ }^{6}$ Professor Adjunto, Departamento de Informática - DPI/UFV; ${ }^{7}$ Professor Adjunto - DFT/UFV. 


\section{INTRODUÇÃO}

A cana-de-açúcar, apesar de possuir mecanismo fotossintético altamente eficiente, apresenta desenvolvimento inicial lento, sendo, por isso, a sua produtividade dependente de um bom manejo de plantas daninhas (Procópio et al., 2003).

Dentre as diversas espécies daninhas infestantes em lavouras de cana-de-açúcar, destaca-se Cyperus rotundus. Esta, além de competir pelos recursos do meio (Silva et al., 2005), libera no solo aleloquímicos (Martini \& Durigan, 2004), que afetam o desenvolvimento dessa cultura.

Por ser uma espécie de difícil controle (Pedrinho Junior et al., 2001) e rápido desenvolvimento em condições de alta luminosidade (Santos et al., 1997), ela domina a área poucas safras após sua introdução. Outra característica de agressividade de $C$. rotundus é a sua reprodução por tubérculos, que armazenam reservas para emissão de novas manifestações epígeas em condições ambientais favoráveis (Webster \& Coble, 1997). A dormência dos tubérculos e de suas sementes botânicas também contribuem para a sua persistência. Nesser et al. (1997) constataram que a meiavida dos tubérculos foi de 16 meses, aproximadamente, com estimativas de viabilidade de até 42 meses no solo. A sua prolificidade, verificada por Rao (1968), com produção de 99 novos tubérculos a partir de apenas um tubérculo viável de $C$. rotundus, em apenas 90 dias, permite refletir sobre a sua capacidade de danos às culturas.

Devido aos seus modos de propagação (tubérculos e semente botânica), os métodos de controle mais eficazes de $C$. rotundus devem diminuir principalmente a densidade e viabilidade dos tubérculos, promovendo a redução da sua população. Segundo Jakelaitis et al. (2003), o uso do método químico associado ao cultural tem propiciado bons resultados em diversas culturas.

Dentre as novas alternativas para o controle químico de $C$. rotundus em cana-deaçúcar, destaca-se a mistura comercial de ametryn + trifloxysulfuron-sodium (Durigan et al., 2004, 2005). Os efeitos distintos de ametryn no controle de dicotiledôneas e de trifloxysulfuron-sodium para monocotiledôneas e algumas dicotiledôneas permite amplo espectro de ação dessa mistura (Rawls et al., 2000). Embora sua recomendação seja para uso em pós-emergência, Martini \& Durigan (2004) destacam a importância do controle químico em estádios precoces da cultura da canade-açúcar, com aplicação em pré-emergência. Também, segundo Troxler et al. (2003), a baixa translocação de trifloxysulfuron-sodium para raízes e tubérculos de $C$. rotundus sugere que a sua aplicação diretamente no solo poderia ser estudada como forma de controle dessa espécie.

Este trabalho teve como objetivo estudar alternativas que pudessem proporcionar maior eficiência no controle químico de $C$. rotundus e sobre sua propagação na cultura da canade-açúcar, utilizando-se a mistura comercial ametryn + trifloxysulfuron-sodium, em diferentes doses e épocas de aplicação em pré e pós-emergência.

\section{MATERIAL E MÉTODOS}

O experimento foi realizado em Viçosa-MG, durante o ano agrícola 2004/05, em área sobre Argissolo Vermelho-Amarelo câmbico, com textura argilosa. O solo coletado $(0-20 \mathrm{~cm})$ apresentou $\mathrm{pH} \mathrm{em} \mathrm{H}_{2} \mathrm{O}$ de 6,7; e P, $\mathrm{Ke} \mathrm{Ca}^{2+}$ de $143,1,250 \mathrm{mg} \mathrm{dm}^{-3} \mathrm{e} 4,0 \mathrm{cmol}_{c} \mathrm{~L}^{-1}$, respectivamente, com elevados teores de matéria orgânica (3,6 dag kg-1) e CTC $\left(7,85 \mathrm{cmol}_{c} \mathrm{dm}^{-3}\right)$. A área selecionada apresentava alta uniformidade de infestação de $C$. rotundus (2.532 r 126 manifestações epígeas $\mathrm{m}^{-2}$ ), a qual foi previamente preparada e sulcada para o plantio da cana, variedade RB 72454.

As parcelas experimentais foram constituídas por quatro linhas espaçadas em 1,2 m de largura, com $5 \mathrm{~m}$ de comprimento cada. A área útil em cada parcela foi representada pelas duas linhas centrais com $4 \mathrm{~m}$ de comprimento, totalizando $9,6 \mathrm{~m}^{2}$. A adubação foi realizada no sulco, juntamente ao plantio, correspondendo a $500 \mathrm{~kg} \mathrm{ha}^{-1}$ da formulação NPK 8-28-16.

No controle de C. rotundus foram usados os tratamentos compostos por algumas combinações das doses $\left(0,0,1,0,1,5\right.$ e 2,0 $\left.\mathrm{kg} \mathrm{ha}^{-1}\right)$, aplicadas em pré ou pós-emergência da mistura comercial ametryn + trifloxysulfuron-sodium, 
conforme apresentado na Tabela 1. A comparação foi realizada utilizando-se os tratamentos: a) 1,0 $\mathrm{kg} \mathrm{ha}^{-1}$ pré $+1,0 \mathrm{~kg} \mathrm{ha}^{-1}$ pós-emergência da mistura comercial ametryn + trifloxysulfuron-sodium; e b) $0,90 \mathrm{~kg} \mathrm{ha}^{-1}$ de sulfentrazone, além das testemunhas com e sem capina, totalizando dez tratamentos (Tabela 1) dispostos em blocos, com quatro repetições.

A aplicação dos herbicidas em pré-emergência foi feita no dia do plantio, com solo úmido, e a de pós-emergência, 30 dias depois, quando as plantas de cana-de-açúcar estavam com 5 a 7 folhas e a tiririca próxima ao estádio de pré-florescimento, com altura média de $30 \mathrm{~cm}$. Foi utilizado pulverizador costal com pressurização de 2,5 Psi, equipado com barra de quatro bicos, Teejet série 110.02, espaçados de $0,5 \mathrm{~m}$ e calibrados para aplicação de $150 \mathrm{~L} \mathrm{ha}^{-1}$. Para manter o tratamento testemunha sem interferência de espécies daninhas, foram necessárias sete capinas manuais, aos 10, 25, 40, 55, 70, 85 e 100 dias após o plantio, quando ocorreu a cobertura do solo pela cultura.

As avaliações dos tratamentos visando o controle de $C$. rotundus foram realizadas aos 30, 60 e 90 dias após aplicação (DAA) em pré-emergência e aos 30 e 60 dias para os tratamentos em pós-emergência, que corresponderam a 30/0, 60/30 e 90/60 DAA pré/pós, respectivamente. Foram avaliadas a densidade e massa seca das manifestações epígeas de C. rotundus, utilizando-se quadros amostradores com as dimensões de 0,3 x 0,3 m. Em cada parcela, foram coletadas duas amostras, ao acaso, na entrelinha, sendo os valores estimados por $\mathrm{m}^{2}$. Avaliaram-se, também, os percentuais de controle da espécie daninha em relação às parcelas testemunhas sem capina e de intoxicação em relação às capinadas, conforme as escalas visuais ALAM (1974) e EWRC (1964), respectivamente. No momento da colheita, foram avaliados o número de colmos viáveis comercialmente por metro linear da área útil de cada parcela e o seu peso, com estimativa da produção ( $\mathrm{t} \mathrm{ha}^{-1}$ ) por tratamento.

Para avaliação dos tubérculos, coletaramse duas amostras de solo de $0,018 \mathrm{~m}^{3}$ cada $(0,30$ x 0,30 x 0,20 m), por parcela, aos 90/60 DAA pré/pós. O solo foi armazenado em sacos plásticos e posteriormente peneirado, sendo separados e avaliados o número e a massa fresca de tubérculos. Estes foram classificados em vivos e mortos, conforme a aparência visual e dureza ao toque, com a fração de tubérculos vivos, selecionada e semeada em vasos, contendo 3,0 L de areia. Para isso, foram separados 20 tubérculos pré-brotados por tratamento, com massa média de 10,64 r $\emptyset, 06 \mathrm{~g}$, apresentando apenas uma brotação visivel. Após 90 dias da semeadura, em vasos mantidos em casa de vegetação, avaliou-se a massa seca das manifestações epígeas para cada tratamento.

Tabela 1 - Doses dos herbicidas em pré e pós-emergência, utilizados no manejo químico de Cyperus rotundus, na cultura da cana-de-açúcar (RB 72454)

\begin{tabular}{|c|c|c|c|}
\hline & \multirow{2}{*}{ Tratamento } & \multicolumn{2}{|c|}{ Doses aplicadas ${ }^{\underline{1}}$} \\
\hline & & \multirow{2}{*}{$\frac{\text { Pré-emergência }}{1,0}$} & \multirow{2}{*}{$\frac{\text { Pós-emergência }}{1,0}$} \\
\hline 1 & Ametryn + Trifloxysulfuron-sodium ${ }^{2 /}$ & & \\
\hline 2 & Ametryn + Trifloxysulfuron-sodium & 1,0 & - \\
\hline 3 & Ametryn + Trifloxysulfuron-sodium & - & 1,0 \\
\hline 4 & Ametryn + Trifloxysulfuron-sodium & 1,5 & - \\
\hline 5 & Ametryn + Trifloxysulfuron-sodium & - & 1,5 \\
\hline 6 & Ametryn + Trifloxysulfuron-sodium & 2,0 & - \\
\hline 7 & Ametryn + Trifloxysulfuron-sodium & - & 2,0 \\
\hline 8 & Sulfentrazone $\mathrm{e}^{3 /}$ & 1,8 & - \\
\hline 9 & Testemunha com capina ${ }^{4 /}$ & - & - \\
\hline 10 & Testemunha sem capina & - & "'-" \\
\hline
\end{tabular}

${ }^{1 /}$ Dose expressa em kg ha ${ }^{-1}$ do produto comercial - volume de calda de $150 \mathrm{~L} \mathrm{ha}^{-1} .{ }^{2 /}$ Mistura comercial Krismat ${ }^{\circledR}$, contendo $731,5 \mathrm{~g}$ de ametryn + $18,5 \mathrm{~g}$ de trifloxysulfuron-sodium por kg. ${ }^{3 /}$ Produto comercial Boral ${ }^{\circledR} 500-\mathrm{SC} .{ }^{4 /}$ Testemunha capinada aos 10, 25, 40, 55, 70, 85 e 100 dias após a aplicação em pré-emergência. 
Os dados das três épocas de avaliação foram submetidos à análise de agrupamento hierárquico, em função das médias de tratamentos, com base no método de ligação média e na distância euclidiana. Posteriormente, após a formação dos grupos, foi avaliado o percentual de acertos do agrupamento, pela análise discriminante. Além disso, foram elaborados gráficos de controle $\overline{\mathrm{x}}$ e $c$ de Shewhart no sistema $3 \sigma$. A avaliação das respostas médias às doses em pré e pós-emergência foi realizada por análise de regressão, sendo o modelo escolhido pela simplicidade e o ajuste feito conforme o significado biológico, a 5\% de probabilidade pelo teste t. $\mathrm{O}$ mesmo teste foi aplicado às estimativas das correlações lineares entre as características avaliadas nos tubérculos.

\section{RESULTADOS E DISCUSSÃO}

De acordo com o dendrograma obtido aos 30/0 DAA pré/pós, observou-se a formação de apenas dois grupos (Figura 1a). O primeiro formado pelos tratamentos 1, 2, 4 e 6, correspondentes, respectivamente, a $1,0 \mathrm{~kg} \mathrm{ha}^{-1}$ pré $+1,0 \mathrm{~kg} \mathrm{ha}{ }^{-1}$ pós-emergência, $1,0,1,5 \mathrm{e}$ $2,0 \mathrm{~kg} \mathrm{ha}^{-1}$ em pré-emergência da mistura comercial de ametryn + trifloxysulfuronsodium, $8\left(1,8 \mathrm{~kg} \mathrm{ha}^{-1}\right.$ em pré-emergência de sulfentrazone) e 9 (testemunha com capina) (Tabela 1), os quais foram semelhantes em, aproximadamente, $73 \%$ e cujas médias do percentual de controle, do número de manifestações epígeas (NME) e da massa seca da parte área (MS) de C. rotundus diferiram apenas do segundo grupo, formado pelo tratamento 10 (testemunha sem capina). Verifica-se, pelas médias dos grupos 1 e 2 (Tabela 2), redução elevada para a MS e NME de C. rotundus, sendo de 74,64 e $55,32 \%$, respectivamente. A maior semelhança entre os tratamentos do grupo 1 foi constatada nos tratamentos com a mistura comercial de ametryn + trifloxysulfuronsodium em pré-emergência $4\left(1,5 \mathrm{~kg} \mathrm{ha}^{-1}\right)$ e 6 $\left(2,0 \mathrm{~kg} \mathrm{ha}^{-1}\right)$, os quais apresentaram 95,5\% de similaridade.

Entretanto, para a avaliação correspondente aos 60/30 DAA pré/pós (Figura 1b), nota-se a formação de quatro grupos distintos. O grupo 1 (tratamentos 1, 3, 5 e 7 - Tabela 1), que recebeu a mistura comercial ametryn + trifloxysulfuron-sodium em pós-emergência, apresentou $88,7 \%$ de semelhança entre os seus tratamentos, com as menores médias de $9,14 \mathrm{~g} \mathrm{~m}^{-2}$ para MS e 386,46 $\mathrm{NME} \mathrm{m}^{-2}$ (Tabela 2). O grupo 3 reuniu os tratamentos 2,4 e 6 (Tabela 1), correspondente à aplicação em pré-emergência de ametryn + trifloxysulfuron-sodium, além do tratamento
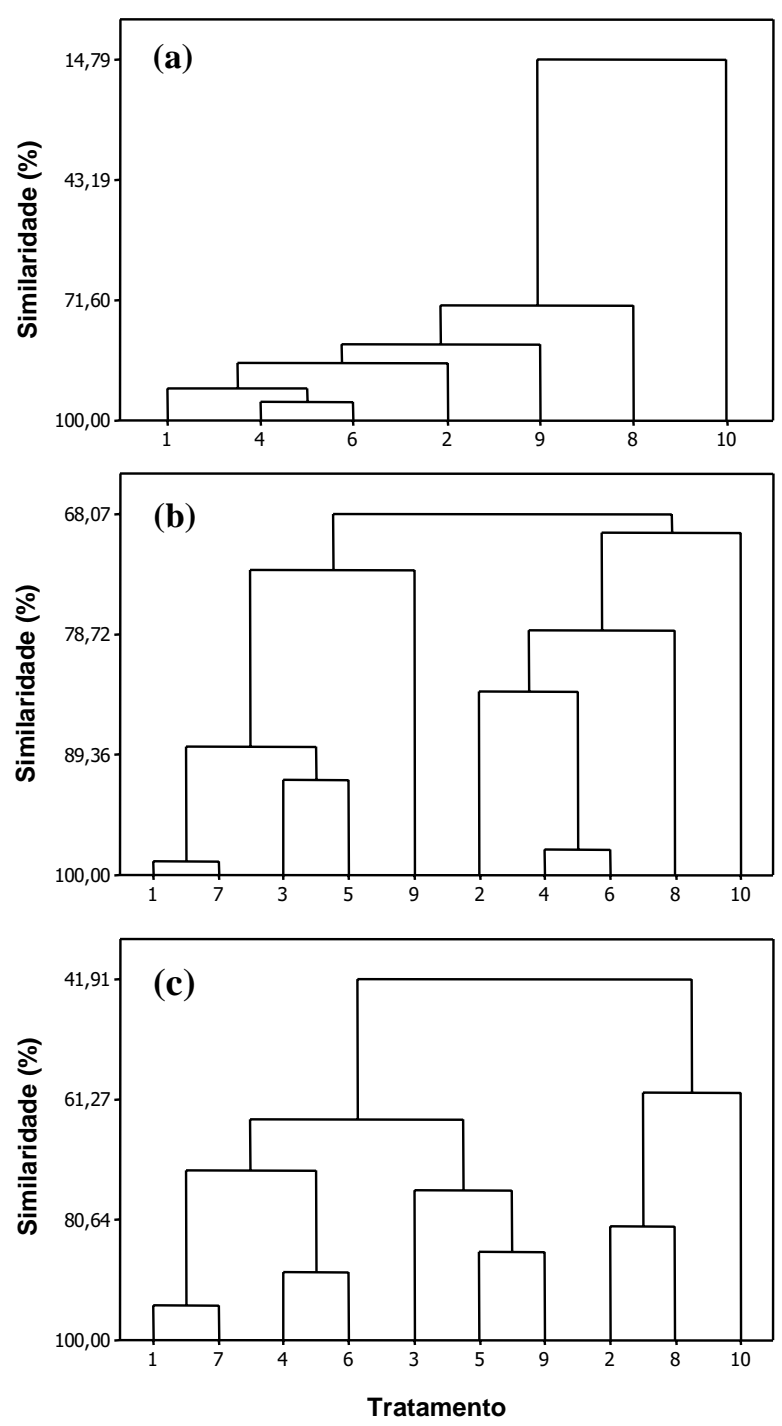

Figura 1 - Dendrogramas de similaridade obtidos com base nas variáveis: controle percentual, número de manifestações epígeas e massa seca da parte aérea de Cyperus rotundus, aos 30/0 (a), 60/30 (b) e 90/60 (c) dias após aplicação (DAA pré/pós-emergência), da mistura comercial de ametryn + trifloxysulfuron-sodium em cana-de-açúcar (RB 72454). Tratamentos apresentados na Tabela 1. 
8, com aplicação de sulfentrazone. A semelhança verificada entre os tratamentos deste grupo foi de $78,72 \%$. Os grupos 2 e 4 foram formados, respectivamente, apenas pelos tratamentos 9 e 10, referentes às testemunhas com e sem capina. Nota-se, na Tabela 2, redução de $31,67 \%$ em relação às médias do percentual de controle do grupo 1 para o grupo 3, embora estes apresentem elevadas diferenças para as variáveis MS e NME. Verificase, também, que apesar de o grupo 2 (testemunha com capina) apresentar satisfatório percentual de controle visual para C. rotundus, o NME foi elevado, com 1.359 plantas $\mathrm{m}^{-2}$. Esse fato é atribuído ao revolvimento do solo, provocando rompimento dos rizomas, ferimento e quebra de dormência nos tubérculos, os quais estimulam o número de manifestações epígeas e a propagação dessa espécie (Nishimoto, 2001). Dados semelhantes também foram observados por Jakelaitis et al. (2003), os quais constataram menor NME no cultivo em plantio direto, em relação ao plantio convencional com revolvimento do solo.
Na avaliação realizada aos 90/60 DAA pré/ pós, observou-se a formação de quatro novos agrupamentos (Figura 1c), sendo as médias por grupo apresentadas na Tabela 2. Verifica-se controle superior a $86 \%$ de $C$. rotundus para os tratamentos 1 (1,0 kg ha-1 pré $+1,0 \mathrm{~kg} \mathrm{ha}^{-1}$ pós de ametryn + trifloxysulfuron-sodium) e 7 (2,0 kg ha ${ }^{-1}$ em pós-emergência de ametryn + trifloxysulfuron-sodium), os quais foram semelhantes em 94,4\%. Embora o grupo 2, formado pelos tratamentos 4 (1,5 kg ha $\mathrm{kg}^{-1}$ pré) e 6 (2,0 kg ha ${ }^{-1}$ pré), tenha apresentado número médio de manifestações epígeas semelhante ao das obtidas pelo grupo 1, a média de MS de C. rotundus foi superior em 225,18\%, com $114,82 \mathrm{~g} \mathrm{~m}^{-2}$. Nota-se que o grupo 4 , formado pelos tratamentos 2 , 8 e 10 (Tabela 1), apresentou as maiores médias para MS e NME (Tabela 2), com semelhança aos demais agrupamentos de apenas 42\% (Figura 1c). O grupo 3 (tratamentos 3, 5 e 9 - Tabela 1), embora tenha apresentado 82,92\% de controle de C. rotundus, não foi eficiente para a redução do NME, com média de 1.509 plantas $\mathrm{m}^{-2}$ (Tabela 2).

Tabela 2 - Estimativa das médias dos grupos de tratamentos utilizados para controle de Cyperus rotundus no cultivo de canade-açúcar (RB 72454), de observações analisadas pelo método de agrupamento hierárquico

\begin{tabular}{|c|c|c|c|c|c|c|c|c|c|}
\hline \multirow{3}{*}{$\begin{array}{c}\text { Época } \\
\text { de avaliação }{ }^{1 /}\end{array}$} & \multirow{3}{*}{ Grupo } & \multirow{3}{*}{ Tratamento } & \multicolumn{6}{|c|}{ Média das observações (parte aérea) } & \multirow{3}{*}{$\begin{array}{l}\% \text { acerto do } \\
\text { agrupamento }\end{array}$} \\
\hline & & & \multicolumn{2}{|c|}{ Controle } & \multicolumn{2}{|c|}{ Massa seca (g) } & & $\begin{array}{l}\text { manifestações } \\
\text { epígeas }\end{array}$ & \\
\hline & & & \multicolumn{2}{|c|}{$(\%)$} & \multicolumn{4}{|c|}{$\left(\mathrm{m}^{-2}\right)$} & \\
\hline \multirow{2}{*}{$1^{\mathrm{a}}$} & 1 & $1-2-4-6-8-9$ & \multicolumn{2}{|c|}{71,25} & \multicolumn{2}{|c|}{115,09} & & $1.131,25$ & \multirow{2}{*}{100} \\
\hline & 2 & 10 & \multicolumn{2}{|c|}{0,00} & \multicolumn{2}{|c|}{453,75} & & $2.531,94$ & \\
\hline \multirow{4}{*}{$2^{\mathrm{a}}$} & 1 & $1-3-5-7$ & \multicolumn{2}{|c|}{80,94} & \multicolumn{2}{|c|}{9,14} & & 386,46 & \multirow{4}{*}{100} \\
\hline & 2 & 9 & \multicolumn{2}{|c|}{90,00} & \multicolumn{2}{|c|}{42,96} & & $1.359,72$ & \\
\hline & 3 & $2-4-6-8$ & \multicolumn{2}{|c|}{55,31} & \multicolumn{2}{|c|}{180,59} & & $1.113,19$ & \\
\hline & 4 & 10 & \multicolumn{2}{|c|}{0,00} & \multicolumn{2}{|c|}{216,53} & & $1.966,67$ & \\
\hline \multirow{4}{*}{$3^{\mathrm{a}}$} & 1 & $1-7$ & \multicolumn{2}{|c|}{86,87} & \multicolumn{2}{|c|}{35,31} & & 679,17 & \multirow{4}{*}{100} \\
\hline & 2 & $4-6$ & & & \multicolumn{2}{|c|}{114,82} & & 690,51 & \\
\hline & 3 & $3-5-9$ & \multicolumn{2}{|c|}{82,92} & \multicolumn{2}{|c|}{86,19} & & $1.509,26$ & \\
\hline & 4 & $2-8-10$ & \multicolumn{2}{|c|}{23,33} & \multicolumn{2}{|c|}{209,57} & & $1.718,21$ & \\
\hline & & & \multicolumn{6}{|c|}{ (tubérculos) } & \\
\hline & & & NTV & NTM & $M V-1$ & MN & & $1 / 2$ & \\
\hline & 1 & $1-6$ & 303,62 & 157,75 & 130,03 & 27, & & 4,65 & \\
\hline $3^{\mathrm{a}}$ & 2 & $2-4-8$ & 386,54 & 215,08 & 164,06 & 35 , & & 4,63 & 100 \\
\hline & 3 & $3-5-7$ & 489,33 & 158,42 & 182,69 & 29, & & 6,12 & \\
\hline & 4 & 10 & 887,50 & 156,12 & 331,46 & 26 , & & 12,31 & \\
\hline
\end{tabular}

1/ $1^{\underline{a}}$ - (30/0 dias após aplicação - DAA pré/pós emergência); $2^{\underline{a}}$ - (60/30 DAA pré/pós); $3^{\text {a }}$ - (90/60 DAA pré/pós). NTV: número de tubérculos vivos; NTM: número de tubérculos mortos; MV-1: massa de tubérculos vivos (g); MM-2: massa de tubérculos mortos (g); 1/2: relação entre a massa de tubérculos vivos e a de mortos. 
A análise de agrupamento para avaliação dos tubérculos em campo (Figura 2) reuniu os tratamentos em quatro grupos distintos, cujas médias encontram-se na Tabela 2. Os grupos formados 1, 2 e 3 foram semelhantes em 74,34, 74,20 e 67,41\%, respectivamente. Embora se verifiquem poucas diferenças entre as médias dos grupos 1, 2 e 3 para número e massa de tubérculos vivos e mortos, o grupo 4 (tratamento testemunha sem capina) foi similar em apenas $22,51 \%$, em relação aos obtidos nos demais (Figura 2). O mesmo apresentou elevado número de tubérculos vivos (887,5 tubérculos $\mathrm{m}^{-2}$ ), com média superior de $125,73 \%$, mas número de tubérculos mortos (NTM) semelhante ao dos demais agrupamentos. Resultados satisfatórios de controle de C. rotundus também foram observados por Durigan et al. (2004), os quais constataram inviabilidade de tubérculos superiores a 50\% para as plantas tratadas com ametryn + trifloxysulfuron-sodium.

Os tratamentos em pós-emergência não se destacaram em nenhuma das características avaliadas para os tubérculos, tendo sido obtidos os piores resultados para a relação entre as massas de tubérculos vivos e mortos (Tabela 2). No que se refere aos tubérculos, verificaram-se, ainda, as correlações $(\mathrm{P}<0,05)$ de 0,98 e 0,99 entre a massa total e o número e massa de tubérculos vivos, respectivamente (Tabela 3). Também ocorreu correlação $(\mathrm{P}<0,05)$ de 0,87 entre o número e a massa de tubérculos mortos. Nas avaliações em casa de vegetação, após 90 dias da semeadura, não foram constatadas diferenças em relação à massa seca da parte aérea de $C$. rotundus entre os tratamentos, com média de 6,98 $\rho$ 0,14 g.

Observando as estimativas das médias da massa seca da parte aérea de $C$. rotundus, para cada tratamento (Figura 3), constatam-se maiores efeitos nas avaliações aos 60/30 DAA pré/pós, cujos valores médios encontram-se mais distanciados da média geral (126,40 g). Observa-se, ainda, que todos os tratamentos em pós-emergência (1, 3, 5 e 7 - Tabela 2), para ametryn + trifloxysulfuron-sodium, apresentaram as menores médias de MS nessa avaliação, juntamente com o tratamento 9 . Entretanto, na última coleta, efetuada aos 90/ 60 DAA pré/pós, verificou-se redução satisfatória de MS de $C$. rotundus apenas nos tratamentos 1, 7 e 9, os quais corresponderam à aplicação de $1,0 \mathrm{~kg} \mathrm{ha}^{-1}$ pré $+1,0 \mathrm{~kg} \mathrm{ha}^{-1}$ pós ou 2,0 $\mathrm{kg} \mathrm{ha}^{-1}$ pós da mistura comercial de ametryn + trifloxysulfuron-sodium e a testemunha capinada, respectivamente. O tratamento 8 com aplicação de sulfentrazone em pré-emergência não reduziu satisfatoriamente, em nenhuma época de avaliação, a MS de C. rotundus. Uma hipótese plausível poderia estar relacionada à sorção desse herbicida no solo, em função da relativamente alta CTC do solo $\left(7,85 \mathrm{cmol}_{\mathrm{c}} \mathrm{dm}^{-3}\right)$ e do teor de matéria orgânica (3,6 dag $\left.\mathrm{kg}^{-1}\right)$. Correlações positivas da CTC com o aumento da capacidade de sorção ao solo pelo sulfentrazone foram constatadas por Kerr et al. (2004).

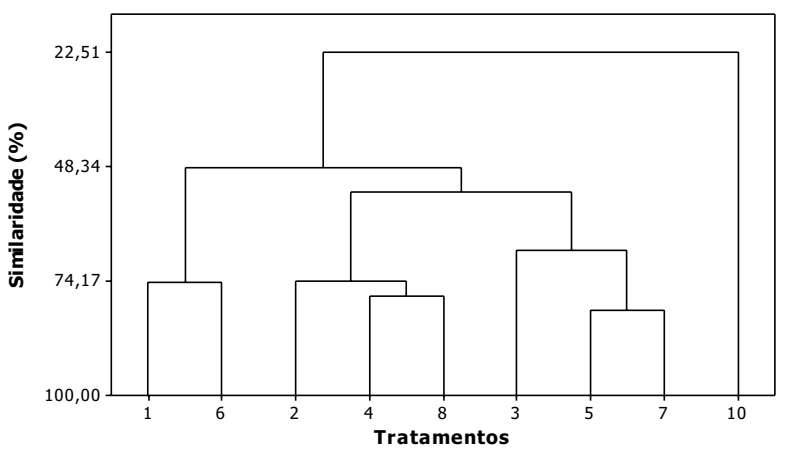

Figura 2 - Dendrograma de similaridade obtido com base nas variáveis: número de tubérculos vivos (NTV); número de tubérculos mortos (NTM); massa de tubérculos vivos (MTV) e mortos (MTM); e relação massa total de tubérculos por MTV de Cyperus rotundus, aos 90/60 dias após aplicação (DAA pré/pós-emergência) da mistura comercial de ametryn + trifloxysulfuron-sodium em cana-de-açúcar (RB 72454). Tratamentos apresentados na Tabela 1.

Tabela 3 - Estimativas das correlações de Pearson obtidas entre as variáveis: massa total de tubérculos de Cyperus rotundus (MT); número de tubérculos vivos (NTV) e mortos (NTM); massa de tubérculos vivos (MTV) e mortos (MTM), respectivamente; e relações entre o número de tubérculos vivos e mortos (NV/NM) e massa total e número de tubérculos vivos (MT/NV) coletados em campo (médias dos tratamentos)

\begin{tabular}{|l|c|c|c|c|c|c|}
\hline Variável & NTV & NTM & MTV & MTM & NV/NM & MT/NV \\
\hline MT & $0,98^{*}$ & $-0,27$ & $0,99^{*}$ & $-0,29$ & $0,96^{*}$ & $-0,60$ \\
\hline NTV & - & $-0,35$ & $0,99^{*}$ & $-0,40$ & $0,97^{*}$ & $-0,69$ \\
\hline NTM & - & - & $-0,32$ & $0,87^{*}$ & $-0,51$ & 0,16 \\
\hline MTV & - & - & - & $-0,35$ & $0,97^{*}$ & $-0,60$ \\
\hline MTM & - & - & - & - & $-0,51$ & $-0,31$ \\
\hline
\end{tabular}

* Significativo pelo teste $\mathrm{t}(\mathrm{P}<0,05)$. 


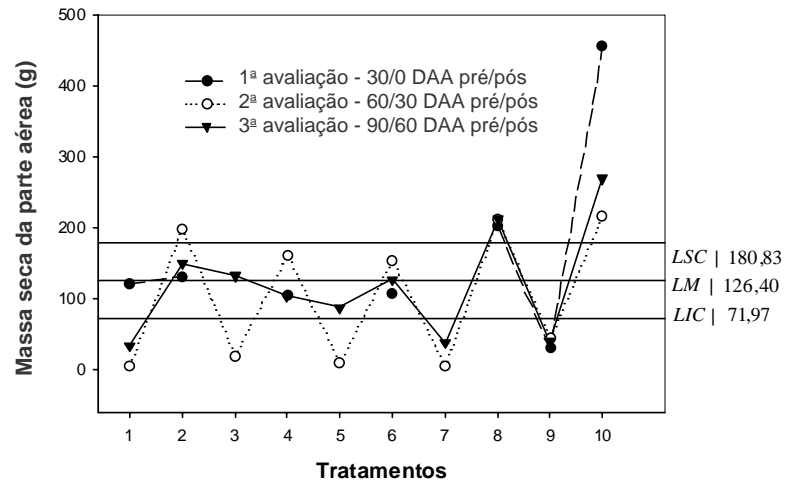

Figura 3 - Estimativa das médias de massa seca da parte aérea de Cyperus rotundus, em função dos tratamentos, para as diferentes épocas de avaliação em campo, na cultura da canade-açúcar RB 72454, no gráfico \& de Shewhart. LSC limite superior de controle, LM - linha média e LIC - limite inferior de controle. Tratamentos apresentados na Tabela 1.

Nas avaliações para NME de $C$. rotundus (Figura 4), observou-se comportamento distinto nos tratamentos em pós-emergência, para a segunda e terceira coletas. Nota-se acentuada redução do NME, aos 30 dias após aplicação, para ametryn + trifloxysulfuron-sodium em pós-emergência. Todavia, esse resultado não se manteve na última avaliação efetuada aos 60 dias após aplicação, na qual o NME aumentou, exceto nas parcelas experimentais que receberam a maior dose de $2,0 \mathrm{~kg} \mathrm{ha}^{-1}$. Portanto, verificou-se que, embora as aplicações em pós-emergência tenham sido eficientes na redução da MS de C. rotundus, as aplicações em pré-emergência apresentaram maior controle e por um período mais prolongado sobre o número de manifestações epígeas. Os tratamentos 1, 4, 6 e 7 (Tabela 1) foram os que proporcionaram maior eficiência na redução do NME até a última avaliação, correspondente aos 90 e 60 DAA em pré e pós-emergência, respectivamente. Para o percentual visual de controle (Figura 5), novamente os tratamentos 1 ( $1,0 \mathrm{~kg} \mathrm{ha}^{-1}$ pré $+1,0 \mathrm{~kg} \mathrm{ha}^{-1}$ pós) e 7 (2,0 $\mathrm{kg} \mathrm{ha}^{-1}$ em pós-emergência), além da testemunha capinada (tratamento 9), apresentaram médias superiores às obtidas nos demais tratamentos, sendo de 87,5, 86,25 e 90,0\%, respectivamente (Figura 5). Porcentagem de controle semelhante também foi obtida por Durigan et al. (2005), com 84,8\% para ametryn + trifloxysulfuron-sodium.

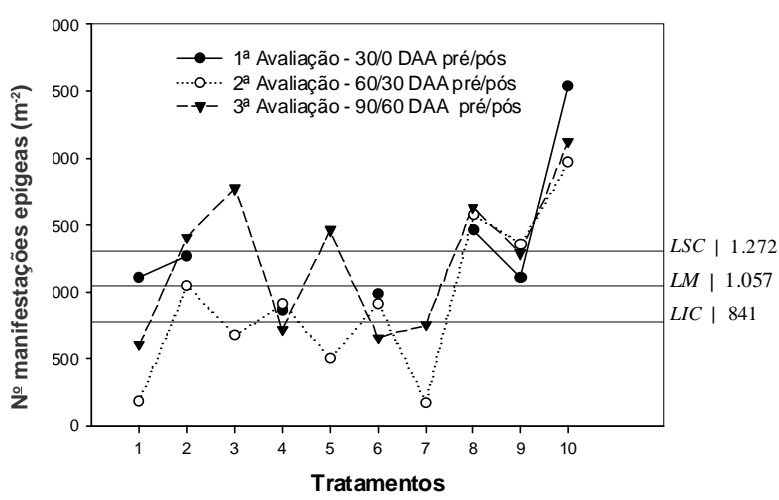

Figura 4 - Estimativa das médias do número de manifestações epígeas de Cyperus rotundus, em função dos tratamentos, para as diferentes épocas de avaliação em campo, na cultura da cana-de-açúcar RB 72454, no gráfico $c$ de controle. LSC - limite superior de controle, LM - linha média e LIC limite inferior de controle Tratamentos apresentados na Tabela 1.

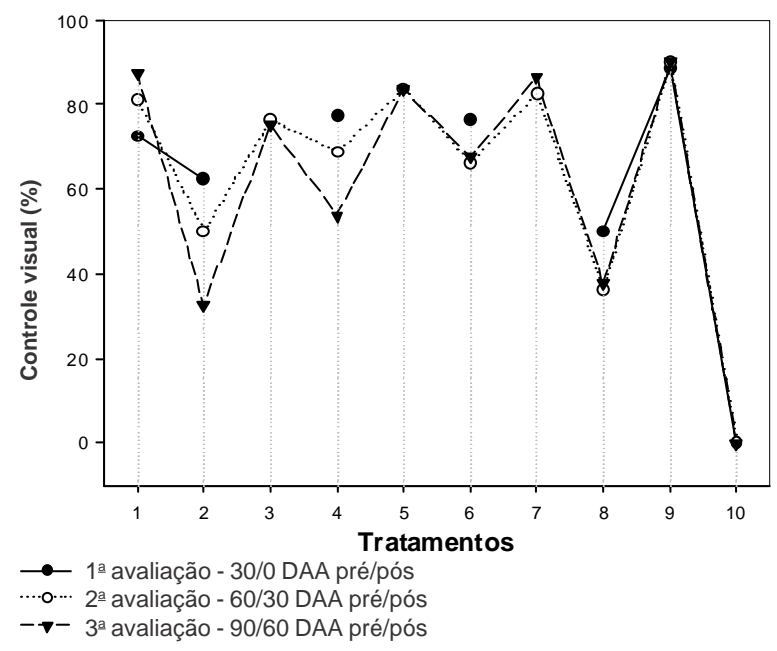

Figura 5 - Estimativa do controle visual percentual de Cyperus rotundus na cultura de cana-de-açúcar, RB 72454, com base na escala da ALAM, para as diferentes épocas de avaliação. Tratamentos apresentados na Tabela 1.

Não foram constatados efeitos de elevada intoxicação na cana-de-açúcar, cultivar RB 72454. Os maiores índices médios verificados foram de 12,5 e $25,0 \%$ nos tratamentos com ametryn + trifloxysulfuron-sodium, na dose de $2,0 \mathrm{~kg} \mathrm{ha}^{-1}$, em pré e pós-emergência, respectivamente, não se observando os sintomas na última avaliação realizada em campo. Ferreira et al. (2005) também não verificaram efeito tóxico sobre RB 72454 de dose de $2,0 \mathrm{~kg} \mathrm{ha}^{-1}$ 
de ametryn + trifloxysulfuron-sodium, demonstrando alta seletividade deste herbicida para essa variedade.

Para as variáveis produção e número de colmos, avaliadas no momento da colheita da cana-de-açúcar (Figura 6), destaca-se o comportamento observado nos tratamentos 1,5 , 6 e 7, além da testemunha capinada (tratamento 9), os quais apresentaram os melhores efeitos de tratamento em relação aos demais. Verifica-se, ainda, concordância parcial dessas variáveis em relação ao controle visual percentual de $C$. rotundus, constatado em campo (Figura 5). A interferência negativa dessa espécie daninha na brotação e produção de colmos de cana-de-açúcar já foi constatada por Keeley (1987), além de resultados semelhantes relatados por Durigan et al. (2004, 2005).

Nas comparações entre as doses de ametryn + trifloxysulfuron-sodium, a resposta para NME ocorreu até $1,14 \mathrm{~kg} \mathrm{ha}^{-1}$, aos 60/ 30 DAA pré/pós, não manifestando efeito $(\mathrm{P}>0,05)$ a partir desta dose (Figura 7$)$. Entretanto, aos 90/60 DAA pré/pós, o comportamento foi linear, com redução no NME de 7,8\% com $2,0 \mathrm{~kg} \mathrm{ha}^{-1}$ de ametryn + trifloxysulfuronsodium em relação a $1,5 \mathrm{~kg} \mathrm{ha}^{-1}$, sendo necessário a maior dose em pré-emergência para manter sua redução. Já a resposta máxima na redução da MS de C. rotundus ocorreu na dose estimada de $1,25 \mathrm{~kg} \mathrm{ha}^{-1}$, não manifestando efeito $(\mathrm{P}>0,05)$ de maiores doses em pré-emergência dessa mistura (Figura 8).

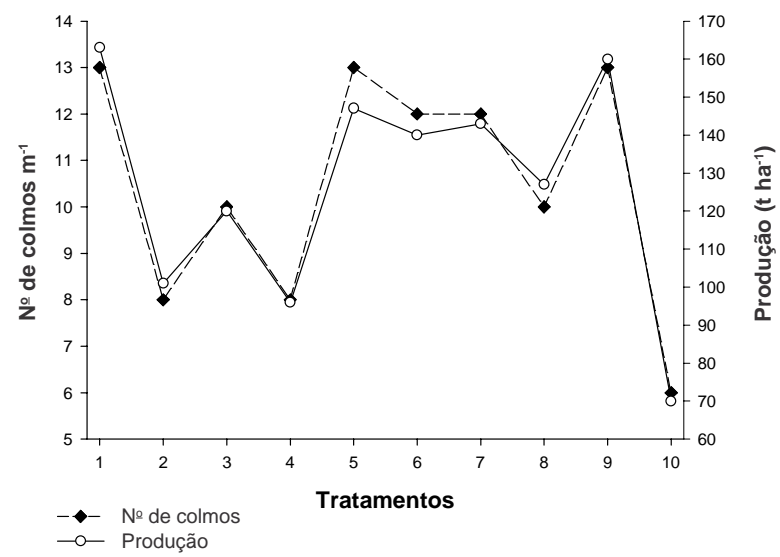

Figura 6 - Número de colmos e estimativa de produção $\left(\mathrm{t}\right.$ ha $\left.{ }^{-1}\right)$ de cana-de-açúcar, avaliados na colheita da variedade RB 72454, em relação aos tratamentos descritos na Tabela 1.
Nas aplicações em pós-emergência de ametryn + trifloxysulfuron-sodium, foi observado comportamento similar para NME, com

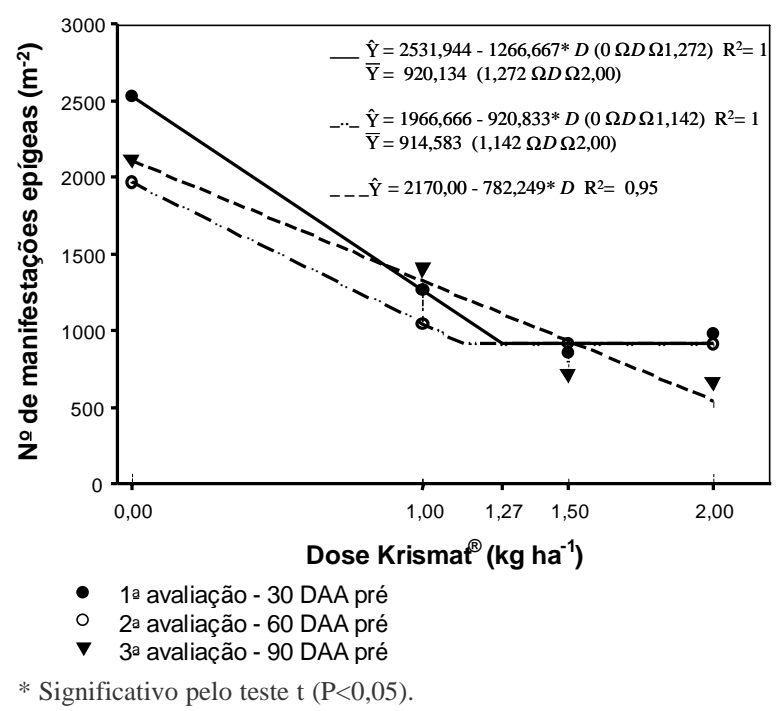

Figura 7 - Estimativa do número de manifestações epígeas de Cyperus rotundus, para as diferentes épocas de amostragem (30, 60 e 90 dias após aplicação do herbicida em préemergência), em função das doses $(D)$ crescentes da mistura comercial Krismat $^{\circledast}(73,15 \%$ de ametryn $+1,85 \%$ de trifloxysulfuron-sodium).

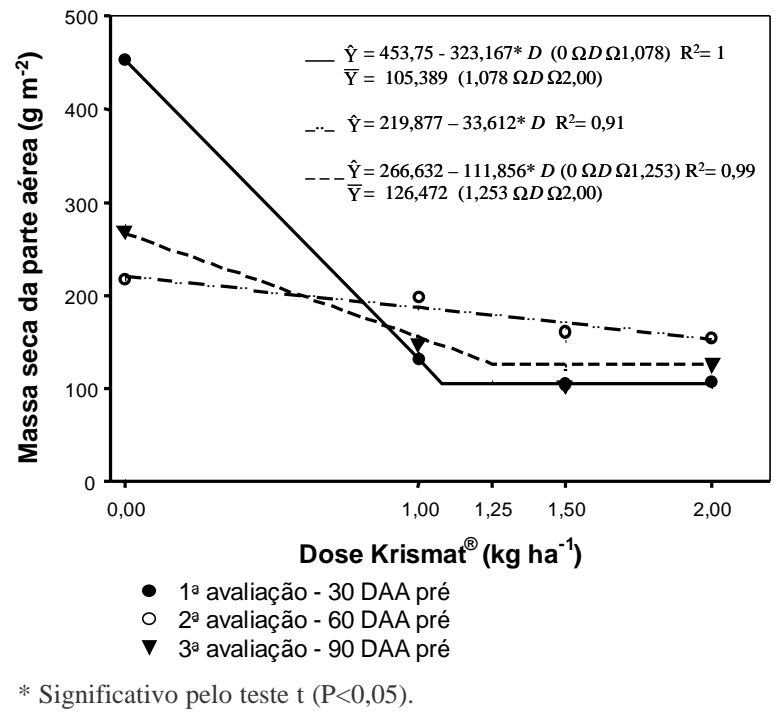

Figura 8 - Estimativas de massa seca da parte aérea de Cyperus rotundus, para as diferentes épocas de amostragem (30, 60 e 90 dias após aplicação do herbicida em pré-emergência), em função das doses $(D)$ crescentes da mistura comercial Krismat $^{\circledR}(73,15 \%$ de ametryn $+1,85 \%$ de trifloxysulfuronsodium). 
necessidade da maior dose $\left(2,0 \mathrm{~kg} \mathrm{ha}^{-1}\right)$ para a manutenção do efeito herbicida aos 60 dias após aplicação (Figura 9). Entretanto, a resposta para as doses em pós-emergência foi mais pronunciada na redução da MS de $C$. rotundus em relação àquela em pré-emergência. O comportamento linear verificado no intervalo de 0,0 a $2,0 \mathrm{~kg} \mathrm{ha}^{-1}$ da mistura comercial desses herbicidas, até os 60 DAA pós-emergência, evidencia a necessidade da maior dose no controle da MS dessa espécie daninha.

Tendo em vista que a espécie $C$. rotundus apresenta rápido crescimento inicial da parte área e de tubérculos, o que intensifica a competição com as culturas, o efeito dos tratamentos constatados em pré-emergência da mistura ametryn + trifloxysulfuron-sodium foi promissor na redução do banco de tubérculos e do número de manifestações epígeas dessa espécie. Verifica-se que o fracionamento da dose de $1,0 \mathrm{~kg} \mathrm{ha}^{-1}$ pré $+1,0 \mathrm{~kg} \mathrm{ha}^{-1}$ em pósemergência (tratamento 1) proporcionou controle eficaz na MS e NME de C. rotundus, mantendo seu efeito aos 90/60 DAA pré/pós. Embora a aplicação fracionada possa representar aumento nos custos de controle, essa

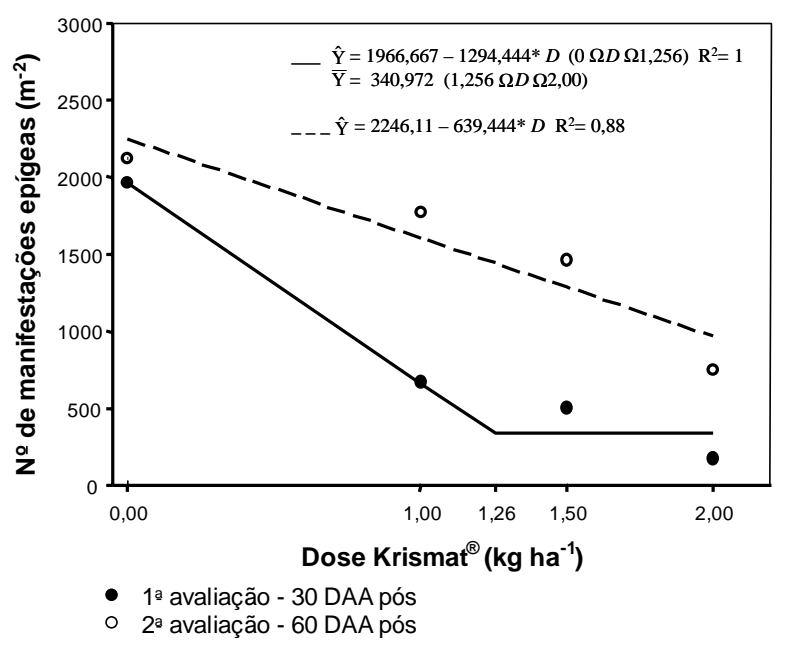

* Significativo pelo teste $\mathrm{t}(\mathrm{P}<0,05)$.

Figura 9 - Estimativas do número de manifestações epígeas de Cyperus rotundus, para as diferentes épocas de amostragem (30 e 60 dias após aplicação do herbicida em pósemergência), em função das doses $(D)$ crescentes da mistura comercial Krismat $^{\circledR}(73,15 \%$ de ametryn $+1,85 \%$ de trifloxysulfuron-sodium).

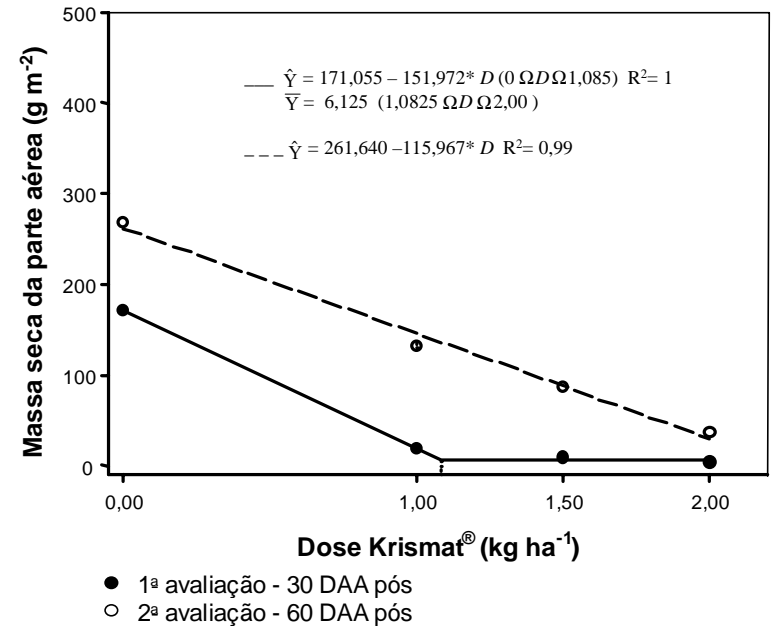

* Significativo pelo teste $\mathrm{t}(\mathrm{P}<0,05)$.

Figura 10 - Estimativas de massa seca da parte aérea de Cyperus rotundus, para as diferentes épocas de amostragem (30 e 60 dias após aplicação do herbicida em pós-emergência), em função das doses $(D)$ crescentes da mistura comercial Krismat $^{\circledR}(73,15 \%$ de ametryn $+1,85 \%$ de trifloxysulfuronsodium).

alternativa pode ser útil na redução de espécies com produção de órgãos propagativos e de armazenamento desde o início do seu estádio vegetativo. Estudos realizados por Tuor \& Froud-Williams (2002) demonstraram que a competição por recursos do solo de C. rotundus foi mais severa que a competição por recursos da parte aérea, o que sugere que métodos de controle em estádios iniciais dessa espécie daninha favoreceriam o estabelecimento da cultura. Além disso, embora a tentativa de redução da dose da mistura comercial de ametryn + trifloxysulfuron-sodium não tenha sido satisfatória no controle de elevada incidência de $C$. rotundus em cana-de-açúcar (2.532 manifestações epígeas $\mathrm{m}^{-2}$ ), estudos que viabilizem doses em função de diferentes níveis de incidência dessa espécie podem colaborar na viabilidade técnica e econômica de seu controle.

\section{LITERATURA CITADA}

ASOCIACIÓN LATINOAMERICANA DE MALEZAS ALAM. Recomendaciones sobre unificación de los sistemas de evaluación en ensayos de control de malezas. ALAM, v. 1, p. 35-38, 1974. 
DURIGAN, J. C. et al. Controle químico da tiririca (Cyperus rotundus) com e sem a cobertura do solo pela palha da canade-açúcar. Planta Daninha, v. 22, n. 1, p. 127-135, 2004.

DURIGAN, J. C. et al. Densidades e manejo químico da tiririca na produtividade de cana-de-açúcar. Planta Daninha, v. 23 , n. 3, p. $463-469,2005$.

\section{EUROPEAN WEED RESEARCH COUNCIL - EWRC.}

Cite of methods in weed research. Weed Res., v. 4, p. 88, 1964.

FERREIRA, E. A. et al. Sensibilidade de cultivares de canade-açúcar à mistura trifloxysulfuron-sodium + ametryn . Planta Daninha, v. 23, n. 1, p. 93-99, 2005.

JAKELAITIS, A. et al. Efeitos de sistemas de manejo sobre a população de tiririca. Planta Daninha, v. 21, n. 1, p. 89-95, 2003.

KEELEY, P. E. Interference and interaction of purple and yellow nutsedges (C. rotundus and C. esculentus) with crops. Weed Technol., v. 1, n. 1, p. 74-81, 1987.

KERR, G. W.; STAHLMAN, P. W.; DILLE, J. A. Soil pH and cation exchange capacity effects sunflower tolerance to sulfentrazone. Weed Technol., v. 18, n. 2, p. 243-247, 2004.

MARTINI, G.; DURIGAN, J. C. Influência do teor de água na superfície do solo sobre a eficácia e seletividade do flazasulfuron, na cultura de cana-de-açúcar. Planta Daninha, v. 22, n. 2, p. 259-267, 2004.

NESSER, C. et al. Survival and dormancy of purple nutsedge (Cyperus rotundus) tubers. Weed Sci., v. 45, p. 784-790, 1997.

NISHIMOTO, R. K. Purple nutsedge tuber sprouting. Weed Biol. Manag., v. 1, p. 203-208, 2001.
PEDRINHO JUNIOR, A. F. F. et al. Controle de tiririca (Cyperus rotundus) na cultura da cana-de-açúcar, com o herbicida imazapic isolado ou em mistura com pendimenthalin. R. Bras. Herb., v. 2, n. 1, p. 23-29, 2001.

PROCÓPIO, S. O. et al. Manejo de plantas daninhas na cultura da cana de açúcar. Viçosa, MG: Universidade Federal de Viçosa, 2003. 150 p.

RAO, J. Studies on the development of tuber in nutgrass and their starch content at different soil depths. Madras Agric. J., v. 55, p. 19-23, 1968.

RAWLS, E. K. et al. CGA-362622: a new herbicide for weed control in sugarcane. Proc. Southern Weed Sci. Soc., v. 53, p. $163,2000$.

SANTOS, B. M. et al. Effects of shading on the growth of nutsedges (Cyperus spp.). Weed Sci., v. 45, p. 670-673, 1997.

SILVA, A. A. et al. Biologia e controle de plantas daninhas. In: ASSOCIAÇÃO BRASILEIRA DE EDUCAÇÃO SUPERIOR - ABEAS. Curso de proteção de plantas daninhas. Brasília: 2005. 260 p.

TROXLER, S. E. et al. Absorption, translocation, and metabolism of foliar-apllied CGA-362622 in purple (Cyperus rotundus) and yellow nutsedge (C. esculentus). Weed Sci., v. 51, p. 94-101, 2003.

TUOR, F. A.; FROUD-WILLIAMS, R. J. Influence of nitrogen on competition between purple nutsedge, maize and soybean. Int. J. Pest. Manag., v. 48, n. 1, p. 73-79, 2002.

WEBSTER, T. M.; COBLE, H. D. Purple nutsedge (Cyperus esculentus) management in corn (Zea mays) and cotton (Gossypium hirsutum) rotations. Weed Technol., v. 11, p. 543-548, 1997. 